\title{
Ageing Municipalities, Gerontocracy and Fiscal Competition
}

\author{
ANNA MONTÉN \\ MARCEL THUM \\ CESIFO WORKING PAPER NO. 2469 \\ CATEGORY 1: PUBlic FinANCE \\ NOVEMBER 2008

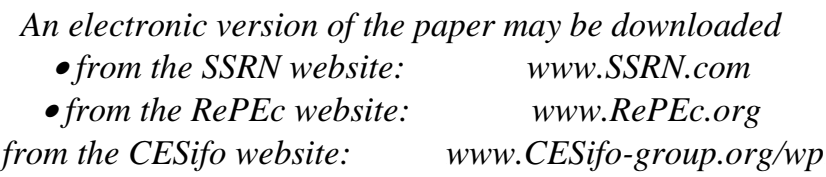




\title{
Ageing Municipalities, Gerontocracy and Fiscal Competition
}

\begin{abstract}
We develop a simple model of fiscal competition among ageing municipalities. When ageing advances, gerontocracies and social planners gradually substitute publicly provided goods aimed at the mobile young population for publicly provided goods for the elderly. This substitution process does not only depend on the ageing itself but also on crowding effects and on the regional distribution of the elderly population. We show that fiscal competition prevents the exploitation of the young. When the share of the elderly is sufficiently large, the utility of the young is even higher in gerontocracies than in welfare maximizing societies. Due to fiscal competition, the gerontocracies will provide even more of the publicly provided good for the young than the social planner.
\end{abstract}

JEL Code: H4, H7.

Keywords: demographic change, fiscal competition, publicly provided goods.

Anna Montén

Faculty of Business and Economics

Technical University Dresden

01062 Dresden

Germany

a.monten@ioer.de
Marcel Thum

Ifo Institute for Economic Research Dresden and Faculty of Business and Economics

University of Dresden

01062 Dresden

Germany

marcel.thum@tu-dresden.de

November 6, 2008

We are grateful to Maximilian von Ehrlich, Robert Fenge, Alexander Kemnitz, Tim Lohse and the participants of the CESifo Conference "Reform of the Welfare State" for very useful suggestions. 


\section{Introduction}

Low birth rates and increased longevity lead to population ageing in many developed countries. This demographic transition will have wide-reaching political, economic and social consequences. Economics literature has so far mostly discussed the macroeconomic impact of ageing societies. This paper focuses on the local level and asks how demographic change will affect the provision of publicly provided goods. On the one hand, as the median voter's age increases the provision of publicly provided goods may shift toward those goods appreciated mostly by the elderly population. On the other hand, the competition among municipalities for the young and mobile intensifies, thus forcing the municipalities to provide more of those goods that make the location attractive for the younger population. In a model of fiscal competition among gerontocratic municipalities, we demonstrate that goods for the elderly are excessively provided in the early phase of a gerontocratic regime. However, when the share of the old population becomes sufficiently large, the effect of fiscal competition dominates and an inefficiently high amount of publicly provided goods for the young population is supplied.

Demographic change will lead to a significant decrease of the population size in many European economies. According to UN projections [United Nations (2007)], the countries in central and eastern Europe will experience the most rapid population loss. Bulgaria and Ukraine are the forerunners in this process and will have lost around 2.4 percent of their 2005 populations by the year $2020 .{ }^{1}$ At the same time, the median age in these two countries will increase from 40.8 to 44.6 years and from 38.9 to 41.9 years respectively. In southern and western Europe, the more significant demographic process will be ageing. Germany's population, will only shrink by 0.12 percent by 2020 . However the median age is projected to increase by as much as 5.2 years from 42.1 years in 2005 to 47.3 years in 2020 . Then only Italy is projected to have an even older population with a median age of 47.5 years. These shifts in the size and age structure can have significant consequences for the economy as a whole. In particular, the impact on capital markets [e.g., Abel (2001), Boersch-Supan et al. (2002), Krueger and Ludwig (2007), Poterba (2001, 2004)] and on public pension schemes [e.g. Breyer and Stolte (2001), Casamatta et al. (2001), Demange and Laroque (1999), Fehr (2000), Sinn and Uebelmesser (2002)] has been extensively studied. $^{2}$ The focus on the aggregate demography often hides that even more pronounced demographic changes occur on the regional or local level.

The changing size and composition of the population poses many challenges for local policymakers. Downsizing of the infrastructure is needed in order to

\footnotetext{
${ }^{1}$ All values pertain to the medium variant of the 2006 revision of the World Population Prospects Database by the Population Division of the Department of Economic and Social Affairs of the United Nations Secretariat, accessible at: http://esa.un.org/unpp.

${ }^{2}$ Breyer and Stolte (2001) and Sinn and Uebelmesser (2002) take a political economy point of view on public pension reforms. Similar to our paper, Sinn and Uebelmesser (2002) consider the power of the old in a gerontocratic society. According to their calculations, Germany will be a gerontocracy in 2016 as pension reforms benefiting the younger cohorts will then become politically unfeasible.
} 
maintain fiscal balances. The portfolio of publicly provided goods has to be adjusted while taking into account the changing age structure. While the younger population may mostly desire access to jobs, schools or child care facilities, the elderly may prefer affordable public transport or safe neighborhoods. The necessary adjustments in the public budget may create conflicts between generations. As the median age increases, majority voting outcomes may shift to benefit the elderly population at the cost of the younger generations. Such generational conflicts in local service provision have been addressed in other contributions, in particular with respect to the provision of public education [e.g. Poterba (1998) for the US and Grob and Wolter (2005) for Switzerland]. On the international level, a gerontocracy may strategically invest in public goods for the young generation, if the elderly benefit from higher future productivity, e.g., via taxes or public pension schemes. Konrad (1995) shows that gerontocracies have an excessive incentive to invest in immobile infrastructure as opposed to mobile human capital. Our model also contains a strategic investment motive on a subnational level. Haupt and Peters (2003) consider an overlapping generations model in which the contribution rates to public pension schemes lead to interregional competition. When the young can strategically migrate, their exploitation by the gerontocracy is limited. The exit option of migration also plays a crucial role in our model. Finally, the studies by Borge and Ratts $\varnothing$ (1995) and Borge and Ratts $\varnothing$ (2008) are closely related to our paper. They mainly focus on local services, such as child care and elderly care, and analyze the negative effect of ageing on the per capita spending on services for the younger cohorts. In contrast to our paper, the influence of local interaction and fiscal competition plays no role.

This contribution examines the effects ageing has on the provision of publicly provided goods at the local level. The young population segments are disadvantaged once the elderly gain the majority, as a gerontocracy will provide less of the impure public goods for the young than would be the case under welfare maximization. However, when ageing proceeds and the elderly have a strong majority, the young will actually receive more than under welfare maximization. This seemingly counterintuitive result appears as fiscal competition for the young intensifies. The local budget depends on the population size, as municipalities are often financed to a large extent through per capita grants. To attract young families, even gerontocratic municipalities are forced to publicly provide goods for younger cohorts. When ageing proceeds, fiscal competition becomes so intensive that the level of the publicly provided goods for the young even exceeds the welfare maximizing level.

We also show that the initial distribution of the population effects the outcome. The paradoxical case where the gerontocracies provide too much of the publicly provided good for the young is more likely when the elderly population is more unequally distributed across municipalities. Regions with large disparities in their age structures may experience a more intensive fiscal competition for the young.

Section 2 describes the setup of the model. In Section 3, we discuss the equilibrium outcomes for gerontocracies that face fiscal competition. Section 
4 derives the social planner's solution. In Section 5, the outcomes from the previous sections are contrasted with one another and the effects of further ageing and changes in the distribution of the elderly are considered. Section 6 concludes.

\section{The Model}

We consider a region with two municipalities. The population of this region consists of both young and old individuals. The fundamental difference between the two population groups is that the young are able to choose the municipality in which they reside, whereas the old segment of the population is immobile. ${ }^{3}$ Each municipality supplies two congestible public goods, one for each population segment. The funding for the publicly provided goods is achieved exclusively through per capita grants. When the population increases, a municipality receives more resources for financing its services. However, when there are more users the individual benefit from the publicly provided good is reduced due to crowding effects. Since the young are mobile between municipalities, their utility maximizing behavior places the municipalities in competition with one another.

\subsection{Municipal Budgets}

There is a fixed total young population, $N$, and each young person must live in one of the two municipalities. Therefore, each municipality has a young population $N_{i}$ where $i=1,2$ stand for the respective municipality and accordingly $N=N_{1}+N_{2}$. Additionally each municipality also has a number of elderly individuals $M_{i}$ where $i=1,2$.

The size of the publicly provided goods for the young and the old are denoted by $Y_{i}$ and $X_{i}$, respectively. The prices of the two goods are normalized to unity. These publicly provided goods have to be financed in each municipality by a transfer from an upper level of government. The municipality receives a per capita block grant of $b{ }^{4}$ The municipal budget constraint thus has the following form:

$$
b\left(N_{i}+M_{i}\right)=Y_{i}+X_{i}, \quad \text { where } i=1,2 .
$$

The assumption of per capita grants captures a stylized fact of many municipal financing schemes in continental Europe. Even when there is some degree of tax autonomy, revenue sharing and equalization schemes make the local budgets de facto dependent on the population size [OECD (2005)]. Transfers and grants

\footnotetext{
${ }^{3}$ Empirically the most mobile age groups are the $20-35$ year-olds. Whereas the older cohorts may not be completely immobile, their mobility is almost insignificant compared to that of the young.

${ }^{4}$ The results of the model do not depend on the simplifying assumption of a single source of finance. The per capita grant only has to be the marginal source of finance.
} 
are intended to achieve horizontal equity in per capita revenue even when tax base disparities exist.

\subsection{Age Group Specific Preferences}

In each municipality, the utility of a young individual depends on the amount of publicly provided goods $\left(Y_{i}\right)$ and on the size of the population in this age group $N_{i}$. In particular, we assume the following utility function:

$$
U_{i}=\left(\frac{Y_{i}}{N_{i}^{\alpha}}\right)^{\beta} \quad i=1,2 .
$$

where $\beta \in(0,1)$ ensures declining marginal utility. The parameter $\alpha \in[0,1]$ determines the degree of congestion. In the extreme cases when $\alpha=0$ and $\alpha=1$, the publicly provided good has the characteristic of a pure public good or a private good, respectively. The intermediate cases, $0<\alpha<1$, capture the empirically relevant phenomenon of partial crowding for many publicly provided goods (Bergstrom and Goodman, 1973; Borcherding and Deacon, 1972). ${ }^{5}$ For simplicity, we exclude spillover effects between the two municipalities, i.e. the utility from locating in municipality $i$ is independent of the level of provision in municipality $j$.

The utility function of a representative old person is analogous to that of a young individual:

$$
V_{i}=\left(\frac{X_{i}}{M_{i}^{\alpha}}\right)^{\beta} \quad i=1,2
$$

For simplicity, we assume identical parameters $\alpha$ and $\beta$ for the young and the old. ${ }^{6}$

\subsection{Location Choice}

Fiscal competition takes place over the bundle of publicly provided goods offered in each of the two municipalities. The municipalities set their levels of publicly provided goods knowing that young individuals can move to the municipality offering the better bundle for the young. For simplicity, we assume costless mobility. Since the relocation decision is intraregional in our case, the costs (both monetary and emotional) associated with mobility should be relatively low. The congestion of the public good will reduce the benefits from the publicly

\footnotetext{
${ }^{5}$ Edwards (1990) discusses the virtues of alternative crowding specifications and finds that this simple decreasing marginal returns specification fares fairly well. Refer to Reiter and Weichenrieder (1997) for a survey of demand estimates of local public goods as well as a discussion of the measurement of crowding.

${ }^{6}$ By construction, the model does not only represent the potential conflict of interest arising between young and old. Instead the framework may also be interpreted in terms of any two groups that demand different publicly provided goods and differ in terms of mobility (e.g., families with children and single households).
} 
provided good as more young move in. ${ }^{7}$ The migration equilibrium is achieved, when a young person is just indifferent between the two municipalities:

$$
U_{1}\left(N_{1}, Y_{1}\right)=U_{2}\left(N_{2}, Y_{2}\right) .
$$

It can easily be verified that the migration equilibrium is stable. Using $N_{2}=N-N_{1}$, the young population in municipality $i$ amounts to

$$
N_{i}^{E}=\frac{N}{\left(\frac{Y_{j}}{Y_{i}}\right)^{\frac{1}{\alpha}}+1}
$$

with $i \neq j$. The equilibrium population in municipality $i$ is only dependent on the provision levels for the young in each municipality, as well as on the total population of young.

\section{Gerontocracies}

When the elderly are in the majority and have have full authority over the allocation decision, a municipality will be considered a gerontocracy. The elderly choose the utility maximizing level of the publicly provided good. Full exploitation of the young generation is prevented by the mobility of the young. Each gerontocracy tries to provide a sufficient level of publicly provided goods for the young to remain competitive and to generate a sufficiently large budget. Hence, the elderly maximize the budget that can be allocated to their own publicly provided good:

$$
\max _{Y_{i}} \quad X_{i}=b \cdot\left(M_{i}+N_{i}^{E}\left(Y_{i}\right)\right)-Y_{i} .
$$

The municipality receives $b$ per inhabitant. The size of the young population depends on the amount of the publicly provided good $Y_{i}$ [see Eq. (5)]. To obtain the budget available for the publicly provided good of the elderly, the expenditure for the young $Y_{i}$ is subtracted from the total budget. From the perspective of a single gerontocracy, the optimal provision of the publicly provided good for the young is implicitly given by

$$
\frac{\partial X_{i}}{\partial Y_{i}}=b \cdot \frac{N}{\left[\left(\frac{Y_{j}}{Y_{i}}\right)^{\frac{1}{\alpha}}+1\right]^{2}} \cdot \frac{Y_{j}^{\frac{1}{\alpha}}}{\alpha \cdot Y_{i}^{\frac{1}{\alpha}+1}}-1=0 .
$$

For $\alpha>\frac{1}{2}$, there is a unique pure strategy equilibrium ${ }^{8}$ with

\footnotetext{
${ }^{7}$ We focus on the provision of publicly provided goods as the sole determinants of location choices. In addition (or alternatively), production may be added to the model. Decreasing marginal productivities limit the inflow of workers and also generate an interior migration equilibrium.

${ }^{8}$ For $\alpha \leq 1 / 2$, no pure strategy equilibrium exists. The details of the derivation and the properties of the mixed strategy equilibrium can be found in Appendix A.
} 


$$
Y_{1}^{G}=Y_{2}^{G}=\frac{b N}{4 \alpha} .
$$

The provision for the young in either municipality does not depend on the share of elderly, but only on the total number of young across both municipalities. Fiscal competition forces the gerontocratic municipalities to spend more on the young population when the per capita transfer $b$ is high, when the young population $N$ is large and when the crowding effects are low (low $\alpha$ ). Using the budget constraint, the equilibrium level of the publicly provided good for the elderly $X_{i}, i=1,2$ amounts to:

$$
X_{i}^{G}=b\left(M_{i}+\frac{N}{2}\left(1-\frac{1}{2 \alpha}\right)\right) .
$$

As $\frac{1}{2}<\alpha<1$, the public provision of the good for the elderly does not only increase in the size of the old population $M_{i}$ but also in the size of young population $N$ as the gerontocracy diverts some resources from the young.

To analyze the impact of ageing on the provision of publicly provided goods, we normalize the size of the total population to unity: $N+M=1$. The share of the elderly in the total population is then defined as $s \equiv \frac{M}{1}$. For notational convenience, we furthermore introduce $m_{i}$ as the share of the elderly population living in municipality $i: m_{i} \equiv \frac{M_{i}}{M_{i}+M_{j}}$. These definitions allow us to write the equilibrium utilities of the young and old in municipality $i$ as

$$
U_{i}^{G}=\left(\frac{b \cdot(1-s)^{1-\alpha}}{2^{2-\alpha} \cdot \alpha}\right)^{\beta}
$$

and

$$
V_{i}^{G}=\left\{b \cdot\left[\left(m_{i} \cdot s\right)^{1-\alpha}+\left(m_{i} \cdot s\right)^{-\alpha} \cdot \frac{1-s}{2} \cdot\left(1-\frac{1}{2 \alpha}\right)\right]\right\}^{\beta},
$$

respectively.

Taking the derivatives of equations (10) and (11) with respect to $s$ yields information on whether the young and the old gain or lose from an ageing society. The utility of the young clearly declines when the share of the elderly increases. The impact on the utility of the elderly, however, is less obvious:

$$
\begin{aligned}
\frac{\partial V_{i}^{G}}{\partial s}= & \beta \cdot\left[V_{i}^{G}\right]^{\beta-1} \cdot b \cdot m_{i}^{-\alpha} \cdot s^{-\alpha-1} . \\
& \left\{s \cdot(1-\alpha) \cdot\left[m_{i}-\frac{1}{2}\left(1-\frac{1}{2 \alpha}\right)\right]-\frac{\alpha}{2}\left(1-\frac{1}{2 \alpha}\right)\right\} .
\end{aligned}
$$

The impact of ageing on the utility of the elderly depends on the expression inside the curly brackets. 


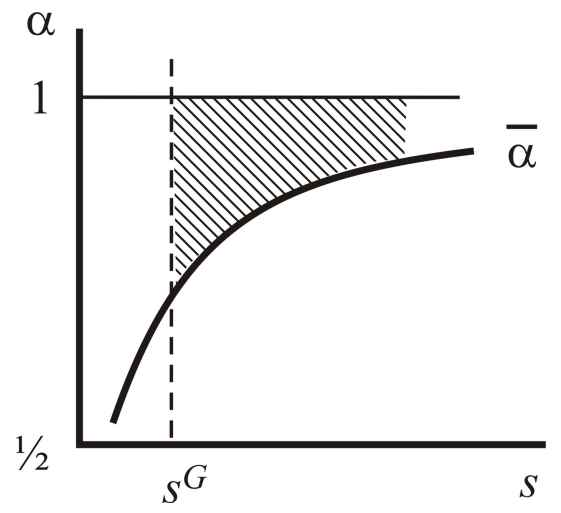

Figure 1: The Impact of Ageing on the Elderly in a Gerontocracy

Proposition 1. In gerontocratic municipalities that face fiscal competition, ageing decreases (increases) the utility of the elderly population if the degree of crowding exceeds (remains below) a critical level $\bar{\alpha}$.

Proof. The impact of ageing on the utility of the elderly depends on the sign of $z \equiv s \cdot(1-\alpha) \cdot\left[m_{i}-\frac{1}{2}\left(1-\frac{1}{2 \alpha}\right)\right]-\frac{\alpha}{2}\left(1-\frac{1}{2 \alpha}\right)$. For $\alpha=\frac{1}{2}$, we get $z\left(\frac{1}{2}\right)=\frac{s m_{i}}{2}>0 . \quad \alpha=1$ yields $z(1)=-\frac{1}{4}$. As $z$ is strictly declining in $\alpha$ $\left(\frac{\partial z}{\partial \alpha}=-s m_{i}-\frac{s}{4 \alpha^{2}}-\frac{1-s}{2}<0\right)$, there is exactly one critical value $\bar{\alpha}$ for which $\frac{\partial V_{i}^{G}}{\partial s} \gtreqless 0 \Leftrightarrow \alpha \lesseqgtr \bar{\alpha}$.

The outcome is illustrated in Figure 1. We measure the share of the elderly $s$ on the horizontal axis and the degree of crowding $\alpha$ on the vertical axis. $s^{G}$ denotes the minimum share of the elderly in society as a whole, necessary to make municipality $i$ a gerontocracy $\left(s \cdot m_{i} \geq \frac{1}{2}(1-s) \Rightarrow s \geq s^{G}=\frac{1}{2 m_{i}+1}\right)$. In a gerontocratic municipality, the gains or losses of the elderly depend on both their share $(s)$ and the characteristics of the publicly provided good $(\alpha)$. The elderly lose from an ageing society for all parameter values $\alpha$ above $\bar{\alpha}$; when $\alpha<\bar{\alpha}$, the old gain from aging. The elderly are more likely to lose from an ageing society when the publicly provided good exhibits strong crowding effects (high $\alpha$ ) because ageing implies that the transfers from young to old have to be shared among a larger number of elderly people. Put differently: If the publicly provided good is closer to a public good, the benefits of the good can be shared among more elderly. As the size of the publicly provided good for the elderly grows with an ageing society, the utility of each old person will increase. Note also that the elderly population in smaller municipalities is more likely to lose from the ageing process; a reduction in the relative size of the elderly in municipality $i$ shifts the $\bar{\alpha}$-curve downwards and increases the shaded area $\left(\partial \bar{\alpha} / \partial m_{i}>0\right)$. Due to fiscal competition the elderly cannot endlessly gain when their majority increases.

In the following, we will derive the social planner's solution and compare the 
outcome with the resource allocation and utilities derived by the two population groups in a gerontocratic society.

\section{Welfare Maximization}

We consider the decision of a utilitarian social planner who maximizes welfare by allocating the budget across municipalities and across the two types of publicly provided goods. The social planner is not restricted to the budget constraints of the individual municipalities but has to obey the aggregate budget constraint. The social planner has no power over individual migration decisions. The mobile young choose the municipality that grants the highest utility. ${ }^{9}$

The social planner maximizes the utilitarian welfare function

$$
W=N_{1} U_{1}+N_{2} U_{2}+M_{1} V_{1}+M_{2} V_{2}
$$

by choosing the sizes of the publicly provided goods for the young $Y_{i}$ and for the elderly $X_{i}(i=1,2)$. She has to take into account the budget constraint ${ }^{10}$

$$
Y_{1}+Y_{2}+X_{1}+X_{2}=b \cdot\left(N_{1}+N_{2}+M_{1}+M_{2}\right)
$$

Since there are economies of scale in the provision of the public services $(\alpha<1)$ and the young are perfectly mobile, it is always optimal for the social planner to provide the public services for the young in one municipality only. The young will be concentrated in this municipality. Hence, the social planner's maximization problem boils down to

$$
\begin{gathered}
\max _{Y, X_{1}, X_{2}} W=N U+M_{1} V_{1}+M_{2} V_{2} \\
\text { s.t. } \quad Y+X_{1}+X_{2}=b \cdot\left(N+M_{1}+M_{2}\right) .
\end{gathered}
$$

The subscript on $Y$ is dropped because the young reside in one community only.

Maximization of the welfare function yields the following provision levels:

$$
\begin{aligned}
Y^{W} & =\frac{b}{N^{\gamma}+M_{1}^{\gamma}+M_{2}^{\gamma}} \cdot N^{\gamma} \\
X_{i}^{W} & =\frac{b}{N^{\gamma}+M_{1}^{\gamma}+M_{2}^{\gamma}} \cdot M_{i}^{\gamma}
\end{aligned}
$$

with $i=1,2$ and $\gamma \equiv \frac{1-\alpha \beta}{1-\beta}$. Note that, due to $\alpha>1 / 2$, we always have $\gamma>1$. The provision levels depend on the aggregate budget constraint and on

\footnotetext{
${ }^{9}$ Alternatively, we could assume that the social planner maximizes welfare for a given distribution of the young population, i.e. half of the young population resides in each municipality as it is the case in the symmetric Nash equilibrium. We discuss alternative specifications of the social planner at the end of this section.

${ }^{10}$ Even though we have normalized the total population to unity, we explicitly keep the size of the distinct population groups in the formula to facilitate interpretation.
} 
the relative share of the population groups. The provision level increases in the size of a population group. Hence, with ageing, the social planner will provide more of the publicly provided goods for the elderly and less for the young.

The more interesting question is how the utilities of the different groups are affected by an ageing society. Using the notation for the share of the elderly $s$ and the distribution of the elderly $m_{1}, m_{2}$, we obtain the utility levels as

$$
\begin{aligned}
U^{W} & =\left[\frac{b \cdot(1-s)^{\frac{1-\alpha}{1-\beta}}}{(1-s)^{\gamma}+s^{\gamma} \cdot\left(m_{1}^{\gamma}+m_{2}^{\gamma}\right)}\right]^{\beta} \\
V_{i}^{W} & =\left[\frac{b \cdot\left(s \cdot m_{i}\right)^{\frac{1-\alpha}{1-\beta}}}{(1-s)^{\gamma}+s^{\gamma} \cdot\left(m_{1}^{\gamma}+m_{2}^{\gamma}\right)}\right]^{\beta}
\end{aligned}
$$

for $i=1,2$. As we have seen before, a decreasing young population will lead to lower provision levels. However, the good also has to be shared among fewer young inhabitants. For the elderly, the larger group size leads to higher provision levels. The larger publicly provided good has to be shared among more users. The net effect of ageing on the utility of the young and the old is summarized in

Proposition 2. (a) With welfare maximization, ageing leads to a lower provision of the publicly provided good for the young and a higher provision for the elderly. (b) Ageing causes a decline of the utility of the young population, whereas the effect on the utility of the old population is ambiguous.

Proof. (a) Immediately follows from the derivatives of (13) and (14). (b) Taking the derivative of $U^{W}$ with respect to $s$ leads to

$$
\frac{\partial U^{W}}{\partial s} \gtreqless 0 \Leftrightarrow \alpha \cdot(1-s)^{\gamma}+s^{\gamma}\left(m_{1}^{\gamma}+m_{2}^{\gamma}\right)\left(\alpha-\frac{\gamma}{s}\right) \gtreqless 0 .
$$

We evaluate the left-hand side at the maximum and show that it will never exceed 0 . Note that $\alpha-\gamma / s<0$. Hence, the left-hand side will be maximized for $m_{1}=m_{2}=\frac{1}{2}$. As the expression grows in $\alpha$, it has to be evaluated at $\alpha=1$, which implies $\gamma=0$. The left-hand side becomes zero at the maximum and therefore $\frac{\partial U^{W}}{\partial s} \leq 0$. For the elderly, the sign of the derivative of $V_{i}$ will depend on

$$
\frac{\partial V_{i}^{W}}{\partial s} \gtreqless 0 \Leftrightarrow(1-s)^{\gamma-1}\left[\frac{1-\alpha}{1-\beta}+\alpha s\right]-\alpha s^{\gamma}\left(m_{1}^{\gamma}+m_{2}^{\gamma}\right) \gtreqless 0 .
$$

For very old societies $(s \rightarrow 1)$, the derivative becomes negative. Hence, the elderly lose from further ageing. For $s=\frac{1}{2}$ and an equally distributed elderly population $m_{1}=m_{2}=\frac{1}{2}$, the derivative is strictly positive. Here, the elderly gain from an ageing society.

As in the case of a gerontocracy, the elderly gain for a certain combination of ageing $(s)$ and crowding $(\alpha)$. However, beyond a certain threshold they lose. 
In Section 5, we compare the impact of ageing on the resource allocation under the social planner and the gerontocrat.

The above approach also allows us to analyze the consequences of heterogeneities in the ageing process. One of the main challenges for ageing societies is the large heterogeneity among municipalities. Whereas one region is still fairly young, the other already has a large number of elderly. How will differences in the number of elderly affect the provision of publicly provided goods? Without loss of generality, let municipality 1 have more old inhabitants than municipality 2: $m_{1}=0.5+\eta$ and $m_{2}=0.5-\eta$ with $\eta \in(0,0.5]$.

Proposition 3. A more unequal distribution of the elderly population reduces the provision of the publicly provided good for the young and, therefore, the utility of this group.

Proof. We rewrite (13) as

$$
Y^{W}=\frac{b \cdot(1-s)^{\gamma}}{(1-s)^{\gamma}+s^{\gamma}\left[(0.5+\eta)^{\gamma}+(0.5-\eta)^{\gamma}\right]} .
$$

Differentiating with respect to $\eta$ yields

$$
\frac{\partial Y^{W}}{\partial \eta}=-Y^{W} \frac{s^{\gamma} \gamma\left[(0.5+\eta)^{\gamma-1}-(0.5-\eta)^{\gamma-1}\right]}{(1-s)^{\gamma}+s^{\gamma}\left[(0.5+\eta)^{\gamma}+(0.5-\eta)^{\gamma}\right]}<0 .
$$

As the size of the young population is fixed, the utility of this group $\left(\frac{Y^{W}}{(1-s)^{\alpha}}\right)^{\beta}$ must also decline when heterogeneity increases.

This result suggests that the young population will suffer more from an ageing society if the elderly population is more unequally distributed across municipalities. An unequal distribution of the immobile old makes it more expensive for the social planner to provide the publicly provided good for the elderly. As a consequence, the provision of the publicly provided good for the young is reduced. The impact of a more unequal population distribution on the elderly is ambiguous. Depending on the size of the elderly population $(s)$ and on the degree of heterogeneity $(\eta)$, the elderly population may gain or lose when the distribution becomes more unequal. The rising cost of provision may be offset by the changing group size.

Due to economies of scale, the provision of the publicly provided good for the mobile young will only take place in one of the two municipalities under welfare maximization. However, this result may not be in line with regional policy which stipulates "equal living conditions" or "equal opportunities" in all regions of a country. By requiring provision for the young in both municipalities (e.g., assuming $Y_{1}=Y_{2}$ ), the effect of such policy can easily be integrated into the current framework. The additional constraint forces the social planner to lower the provision for both young and old. The qualitative effects of ageing, however, remain the same. For simplicity, we adhere to the first-best welfare solution in the subsequent section. 


\section{Comparison of the Gerontocracy and Welfare Maximization}

The two preceding sections have shown that, with both gerontocracy and welfare maximization, ageing leads to a lower provision of publicly provided goods for the young and a higher provision for the elderly. Dominance of the elderly in a gerontocracy would suggest that the provision of the publicly provided good for the young remains on an inefficiently low level in gerontocratic municipalities. However, the exploitation of the young is limited as the municipalities have to compete for the mobile young. This raises the question whether the provision of the publicly provided good for the young remains on an inefficiently low level in gerontocracies or whether, due to fiscal competition, the provision may even exceed the welfare maximizing level beyond a certain level of ageing.

In order to compare the provision levels in the two scenarios (gerontocracy and social planner), we rewrite the provision level for the young in a gerontocracy [see Eq. (8)] as

$$
Y^{G}=\frac{b \cdot(1-s)}{4 \alpha}
$$

and in the case of a social planner [see Eq. (13)] as

$$
Y^{W}=\frac{b \cdot(1-s)^{\gamma}}{(1-s)^{\gamma}+s^{\gamma} \cdot\left(m_{1}^{\gamma}+m_{2}^{\gamma}\right)} .
$$

Note that the comparison is carried out for gerontocratic societies $\left(s \geq \frac{1}{2}\right)$ and for publicly provided goods with some crowding $(\alpha \in[0.5,1])$. Rearranging the terms leads to

$$
Y^{W} \gtreqless Y^{G} \Leftrightarrow[4 \alpha-(1-s)] \cdot(1-s)^{\gamma-1} \gtreqless s^{\gamma} \cdot\left(m_{1}^{\gamma}+m_{2}^{\gamma}\right)
$$

This comparison yields

Proposition 4. The publicly provided good for the young is provided on an inefficiently low level for 'young' gerontocracies but is provided on an inefficiently large scale for 'old' gerontocracies.

Proof. Define $l h s \equiv[4 \alpha-(1-s)] \cdot(1-s)^{\gamma-1}$ and $r h s \equiv s^{\gamma} \cdot\left(m_{1}^{\gamma}+m_{2}^{\gamma}\right)$. The right-hand side of $(23)$ increases in $s\left(\frac{\partial r h s}{\partial s}>0\right)$. Differentiating the left-hand side of (23) yields $\frac{\partial l h s}{\partial s}=(1-s)^{\gamma-2} \cdot[-(\gamma-1) 4 \alpha+\gamma(1-s)]$. The left-hand side of (23) has a maximum at $s=1-\frac{\gamma-1}{\gamma} 4 \alpha<1$, as $\frac{\partial^{2} l h s}{\partial s^{2}}<0$. We have $l h s>r h s$ at $s=0.5$ and $l h s<r h s$ at $s=1$. Hence, there is one critical level $s_{0}$ for which $s \gtreqless s_{0} \Leftrightarrow Y^{G} \gtreqless Y^{W}$.

When the elderly gain the majority in a society, a gerontocracy will initially use its power to exploit the young. The provision of the publicly provided good for the young remains on an inefficiently low level. Accordingly, the provision of 
the publicly provided good for the elderly is excessively large. However, when the society grows older, fiscal competition eventually forces the gerontocracy to provide more of the publicly provided good than the social planner.

This results in the critical level $s_{0}$, beyond which an ageing society provides an excessive amount of publicly provided goods for the young. The variable $s_{0}$ can be used to carry out some interesting comparative statics. Let

$$
e \equiv\left[4 \alpha-\left(1-s_{0}\right)\right] \cdot\left(1-s_{0}\right)^{\gamma-1}-s_{0}^{\gamma} \cdot\left((0.5+\eta)^{\gamma}+(0.5-\eta)^{\gamma}\right)
$$

where we have replaced $m_{1}$ and $m_{2}$ with $0.5+\eta$ and $0.5-\eta$, respectively, to analyze the impact of a more unequal distribution of the elderly population. Differentiating (24) immediately yields $\frac{\partial e}{\partial s_{0}}<0$ (see the Proof to Proposition 4) and $\frac{\partial e}{\partial \eta}<0$. Differentiating with respect to the crowding parameter $\alpha$ leads to

$$
\begin{aligned}
\frac{\partial e}{\partial \alpha}= & 4\left(1-s_{0}\right)^{\gamma-1}-\frac{b}{1-b} s^{\gamma} . \\
& \left\{(0.5+\eta)^{\gamma}\left[\ln \left(1-s_{0}\right)-\ln \left(s_{0}\right)-\ln (0.5+\eta)\right]+\right. \\
& \left.+(0.5-\eta)^{\gamma}\left[\ln \left(1-s_{0}\right)-\ln \left(s_{0}\right)-\ln (0.5-\eta)\right]\right\}
\end{aligned}
$$

Numeric evaluation of this expression shows that $\frac{\partial e}{\partial \alpha}>0$. Hence, we get the following comparative statics results:

$$
\frac{d s_{0}}{d \eta}=-\frac{\partial e / \partial \eta}{\partial e / \partial s_{0}}<0
$$

and

$$
\frac{d s_{0}}{d \alpha}=-\frac{\partial e / \partial \alpha}{\partial e / \partial s_{0}}>0 .
$$

The excessive provision of the publicly provided good for the young is reached earlier, i.e. with a lower share of the elderly $s$, when the population is more unequally distributed across the municipalities $(\eta)$ and when the publicly provided good exhibits less crowding (lower $\alpha$ ).

So far we have focused on a comparison of the provision levels. However, since the provision level is dependent on the number of users, the utility levels achieved by the population should be considered. We can immediately state that the utility of the young will be higher in a gerontocracy if the gerontocracy provides more publicly provided goods for the young than the social planner. Note that the gerontocracies provide the publicly provided good in each municipality whereas the social planner concentrates her expenditures for the young in one municipality. Hence, the larger publicly provided good has to be shared among fewer young people in a gerontocracy. In this case, the young must be better off in a gerontocracy. Even with a slightly smaller provision level in gerontocracies, the young may gain due to the fiscal competition effect. To obtain the general condition for the young being better off in a gerontocracy, we compare the utility levels in the two scenarios. The utility of the young is 


$$
U_{i}^{G}=\left(\frac{b \cdot(1-s)^{1-\alpha}}{2^{2-\alpha} \cdot \alpha}\right)^{\beta}
$$

in a gerontocracy [see Eq. (10)] and

$$
U^{W}=\left(\frac{b \cdot(1-s)^{\frac{1-\alpha}{1-\beta}}}{(1-s)^{\gamma}+s^{\gamma} \cdot\left(m_{1}^{\gamma}+m_{2}^{\gamma}\right)}\right)^{\beta}
$$

with a social planner [see Eq. (15)]. The comparison of the utility of a young person in a gerontocracy and in a welfare maximizing society then yields

$$
U^{W} \gtreqless U^{G} \Leftrightarrow\left[2^{2-\alpha} \alpha-(1-s)\right] \cdot(1-s)^{\gamma-1} \gtreqless s^{\gamma} \cdot\left(m_{1}^{\gamma}+m_{2}^{\gamma}\right) .
$$

This comparison has the same qualitative structure as Eq. (23), where the provision quantities of the two scenarios are compared. Let $\bar{s}$ denote the critical share of the elderly where the utilities the young achieve are the same in a gerontocracy and in a welfare maximizing society $\left(U^{W}=U^{G}\right)$. As we have $2^{2-\alpha} \leq 4$, we immediately get $\bar{s} \leq s_{0}$. This implies that $U^{G}>U^{W}$ occurs 'sooner', i.e. at a lower $s$, than for the case when $Y^{G}>Y^{W}$. The young arrive at inefficiently low utility levels in moderate gerontocracies. However, when society grows older, the young even benefit. Due to fiscal competition, their utility exceeds the welfare maximizing level.

\section{Conclusion}

We have developed a simple framework that allows us to analyze the fiscal competition of ageing municipalities. The ageing of a society will lead to shifts in the provision of public services. When ageing advances, it is optimal from a welfare maximizing point of view to gradually substitute publicly provided goods aimed at the young population with publicly provided goods preferred by the elderly population. This substitution process does not only depend on the ageing itself but also on the degree of crowding and on the regional distribution of the elderly population.

Once the elderly gain the majority in society, they use their power to reduce the provision of the publicly provided good for the young to an inefficiently low level. As our analysis has shown, the downscaling of the provision of the publicly provided good proceeds even slower in a gerontocracy than in a welfare maximizing society. The driving force behind this phenomenon is the fiscal competition for the mobile young among the municipalities. When the share of the elderly is sufficiently large, the utility of the young is higher in gerontocracies than in welfare maximizing societies. Ultimately, the gerontocracies will provide even more of the publicly provided good for the young than the social planner. Put differently: The threat of ageing towns is not so much the exploitation of the young but rather the excessive incentives for making municipalities attractive for the mobile young. The enormous investments in sports facilities and in 
family-friendly environments which currently occur in the rapidly ageing rural areas in eastern Germany may already be telling examples of this trend.

To our knowledge, this paper is the first attempt to analyze the consequences of fiscal competition in ageing societies. Our approach is admittedly simple to highlight the main driving forces of this process. Many open questions remain for future research. First, we have focused on the ageing process but a declining population size may also result from the ongoing demographic transition. Second, generations may be linked by altruistic motives. The elderly may care for the well-being of their children. Such intergenerational links may also create barriers to mobility for the young, which affects fiscal competition and may even lead to path dependence in the population distribution. Third, the complexity of municipal decision-making goes far beyond the simple provision of two types of publicly provided goods. Alternative means of financing through taxes may change the provision levels of publicly provided goods. Municipalities do not only compete for households but also for firms. Attracting new investments may create jobs and generate a subsequent inflow of households. Finally, changes in the size of publicly provided goods often entail considerable adjustment costs that have to be taken into account.

\section{A Appendix: Mixed strategy equilibrium}

In the case of two gerontocracies, there is a unique pure strategy equilibrium for $\alpha \geq 1 / 2$. However, when $\alpha<1 / 2$, only a mixed strategy equilibrium exists. In the following, we derive the equilibrium properties of the gerontocratic solution in detail.

The first order condition for municipality $i$ is (see Section 3):

$$
F O C_{i} \equiv b \cdot \frac{N}{\left[\left(\frac{Y_{j}}{Y_{i}}\right)^{\frac{1}{\alpha}}+1\right]^{2}} \cdot \frac{Y_{j}^{\frac{1}{\alpha}}}{\alpha \cdot Y_{i}^{\frac{1}{\alpha}+1}}-1=0 .
$$

In order to determine the reaction function, we differentiate the first-order condition with respect to $Y_{i}$ and $Y_{j}$.

$$
\frac{\partial F O C}{\partial Y_{i}}=\frac{b N}{\alpha^{2}} Y_{j}^{\frac{1}{\alpha}}\left(\left(\frac{Y_{j}}{Y_{i}}\right)^{\frac{1}{\alpha}}+1\right)^{-3} Y_{i}^{-\frac{2}{\alpha}-2}\left[(1-\alpha) Y_{j}^{\frac{1}{\alpha}}-(1+\alpha) Y_{i}^{\frac{1}{\alpha}}\right]
$$

and

$$
\frac{\partial F O C}{\partial Y_{j}}=\frac{b N}{\alpha^{2}} Y_{i}^{-\frac{1}{\alpha}-1}\left(\left(\frac{Y_{j}}{Y_{i}}\right)^{\frac{1}{\alpha}}+1\right)^{-3} Y_{j}^{\frac{1}{\alpha}-1}\left(-\left(\frac{Y_{j}}{Y_{i}}\right)^{\frac{1}{\alpha}}+1\right) .
$$

Equation (32) gives the second-order condition. In equilibrium, we need 


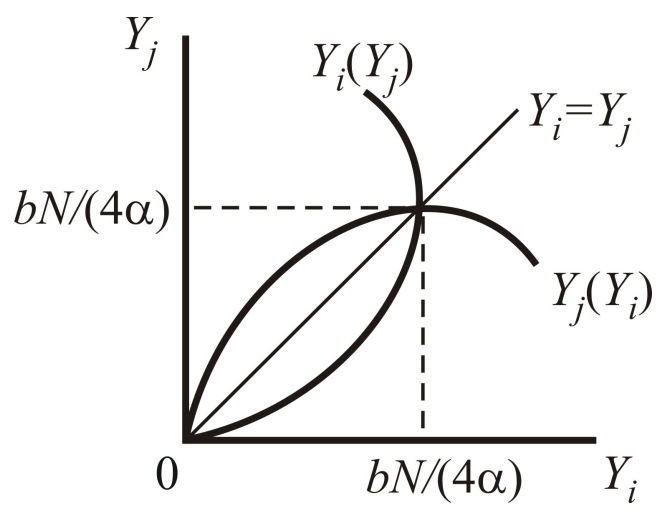

Figure 2: The Pure Strategy Equilibrium

$$
\frac{\partial F O C}{\partial Y_{i}}<0 \Leftrightarrow Y_{i}>\left(\frac{1-\alpha}{1+\alpha}\right)^{\alpha} Y_{j}
$$

for a local maximum. The slope of municipality $i$ 's reaction function is given by

$$
\frac{d Y_{i}}{d Y_{j}}=-\frac{\partial F O C / \partial Y_{j}}{\partial F O C / \partial Y_{i}}=\frac{Y_{i}}{Y_{j}} \frac{Y_{i}^{\frac{1}{\alpha}}-Y_{j}^{\frac{1}{\alpha}}}{(1+\alpha) Y_{i}^{\frac{1}{\alpha}}-(1-\alpha) Y_{j}^{\frac{1}{\alpha}}} .
$$

The reaction function has a positive slope for $Y_{i}<Y_{j}$ and a negative slope for $Y_{i}>Y_{j}$ (as long as the second-order condition is fulfilled). Figure 2 illustrates the equilibrium in pure strategies.

There is a unique symmetric equilibrium with $Y_{i}=Y_{j}=\frac{b N}{4 \alpha}$. So far, we have neglected the possibility that the municipalities are worse off when competing for the young. If a municipality has to spend more on the young than it receives via the per capita grant, it will be better off by withdrawing from fiscal competition. Hence, in equilibrium, the expenditures on the young must not exceed the grants received for the young $\left(\frac{b N}{4 \alpha} \leq \frac{b N}{2}\right)$, which is the case for $\alpha \geq 1 / 2$.

For $\alpha<1 / 2$, the participation constraints for the municipalities become binding and, therefore, the reaction function exhibits a discontinuity (see Figure 3). For low provision levels in municipality $j$, muncipality $i$ competes for the young by providing a positive amount of the publicly provided good. However, when the provision in municipality $j$ exceeds the threshold level $\tilde{Y}_{j}$, the participation constraint becomes binding for municipality $i$ and it reacts with zero provision for the young. We first determine the threshold $\tilde{Y}_{j}$ and then show that the provision of $\tilde{Y}_{j}$ in one municipality and a randomization of provision in the other municipality is an equilibrium.

The threshold for municipality $i$ is reached when it spends as much on the publicly provided good as it receives in grants for the young: $b \cdot N_{i}=Y_{i}$. Substituting the equilibrium migration from (5) and solving for $Y_{j}$ yields 


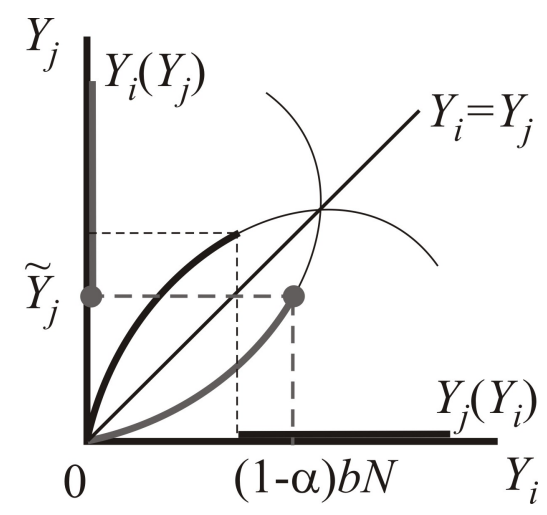

Figure 3: The Mixed Strategy Equilibrium

$$
Y_{j}=\left(\frac{b N}{Y_{i}}-1\right)^{\alpha} \cdot Y_{i}
$$

This expression determines all provisions of publicly provided goods $\left(Y_{i}, Y_{j}\right)$ where municipality $i$ is indifferent between providing $Y_{i}$ and nothing for the young. In addition, the provision of $Y_{i}$ has to be a local optimum for municipality $i$. Therefore, we substitute (36) into the first-order condition (31) and obtain $Y_{i}=(1-\alpha) \cdot b \cdot N$ and $\tilde{Y}_{j}=\alpha^{\alpha} \cdot(1-\alpha)^{(1-\alpha)} \cdot b \cdot N$. If municipality $j$ plays $\tilde{Y}_{j}$, municipality $i$ is just indifferent between $Y_{i}=(1-\alpha) \cdot b \cdot N$ and $Y_{i}=0$.

For an equilibrium, municipality $i$ must choose the alternatives $Y_{i}=(1-$ $\alpha) \cdot b \cdot N$ with probability $p^{H}$ and $Y_{i}=0$ with probability $1-p^{H}$ such that municipality $j$ finds it optimal to play $\tilde{Y}_{j}$. The expected utility of municipality $j$ amounts to

$$
\begin{aligned}
E\left[U_{j}\left(Y_{j}\right)\right]= & p^{H}\left(b\left(M_{j}+N_{j}\right)-Y_{j}\right)+\left(1-p^{H}\right)\left(b\left(M_{j}+N\right)-Y_{j}\right)= \\
& b M_{j}+p^{H} \frac{b N}{\left(\frac{(1-\alpha) b N}{Y_{j}}\right)^{1 / \alpha}+1}+\left(1-p^{H}\right) b N-Y_{j} .
\end{aligned}
$$

We get the first order condition for an optimal choice of $Y_{j}$ by differentiating the expected utility:

$$
\frac{\partial E\left[U_{j}\left(Y_{j}\right)\right]}{\partial Y_{j}}=p^{H} \frac{b N}{\left[\left(\frac{(1-\alpha) b N}{Y_{j}}\right)^{1 / \alpha}+1\right]^{2}} \frac{[(1-\alpha) b N]^{1 / \alpha}}{\alpha Y_{j}^{1 / \alpha+1}}-1=0 .
$$

Substituting $Y_{j}=\tilde{Y}_{j}$ and solving for $p^{H}$ yields

$$
p^{H}=\left(\frac{\alpha}{1-\alpha}\right)^{\alpha}<1 .
$$


It is easy to verify from the second order condition that $\tilde{Y}_{j}$ is indeed a maximum $\left[\frac{\partial^{2} E\left[U_{j}\left(Y_{j}\right)\right]}{\partial Y_{j}^{2}}<0\right]$. In the mixed strategy equilibrium, municipality $i$ chooses $Y_{i}=(1-\alpha) \cdot b \cdot N$ with probability $p^{H}=\left(\frac{\alpha}{1-\alpha}\right)^{\alpha}$ and $Y_{i}=0$ with probability $1-p^{H}$. Municipality $j(j \neq i)$ plays $\tilde{Y}_{j}$.

\section{References}

ABEL, A. B. (2001). Will bequests attenuate the predicted meltdown in stock prices when baby boomers retire? The Review of Economics and Statistics, 83 (4), 589-595.

Bergstrom, T. C. and Goodman, R. P. (1973). Private demand for public goods. American Economic Review, 63, 280-296.

Boersch-Supan, A., Ludwig, A. and Winter, J. (2002). Ageing and international capital flows. In A. J. Auerbach and H. Herrmann (eds.), Ageing, financial markets and monetary policy, Heidelberg: Springer, pp. 55-83.

Borcherding, T. and Deacon, R. (1972). The demand for the services of non-federal governments. American Economic Review, 62, 891-901.

Borge, L.-E. and RAtTs $\varnothing$, J. (1995). Demographic shift relative cost and the allocation of local public consumption in Norway. Regional Science and Urban Economics, 25, 705-726.

— and - (2008). Young and old competing for public welfare services. CESifo Working paper No. 2223.

Breyer, F. and Stolte, K. (2001). Demographic change, endogenous labor supply and the political feasibility of pension reform. Journal of Population Economics, 14 (3), 409-424.

Casamatta, G., Cremer, H. and Pestieau, P. (2001). Demographic shock and social security: A political economy perspective. International Tax and Public Finance, 8 (4), 417-431.

Demange, G. and Laroque, G. (1999). Social security and demographic shocks. Econometrica, 67 (3), 527-542.

EDWARDs, J. H. (1990). Congestion function specification and the 'publicness' of local public goods. Journal of Urban Economics, 27 (1), 80-96.

FeHr, H. (2000). Pension reform during the demographic transition. Scandinavian Journal of Economics, 102 (3), 419-43.

Grob, U. and Wolter, S. C. (2005). Demographic change and public education spending: a conflict between young and old? CESifo Working Paper No. 1555 . 
Haupt, A. and Peters, W. (2003). Voting on public pensions with hands and feet. Economics of Governance, 4 (1), 57-80.

KONRAD, K. A. (1995). Fiscal federalism and intergenerational redistribution. FinanzArchiv, 52 (2), 166-181.

Krueger, D. and Ludwig, A. (2007). On the consequences of demographic change for rates of returns to capital, and the distribution of wealth and welfare. Journal of Monetary Economics, 54 (1), 49-87.

OECD (2005). National sources and OECD Revenue statistics 1965-2004. Revenue structure of sub-central governments, 2002. OECD, Paris.

Poterba, J. M. (1998). Demographic change, intergenerational linkages, and public education. American Economic Review, 88 (2), 315-320.

- (2001). Demographic structure and asset returns. The Review of Economics and Statistics, 83 (4), 565-584.

- (2004). Impact of population aging on financial markets in developed countries. Economic Review, 89 (4), 43-53.

Reiter, M. and Weichenrieder, A. (1997). Are public goods public? A critical survey of the demand estimates for local public services. Finanzarchiv, $\mathbf{5 4}, 374-408$.

Sinn, H.-W. and Uebelmesser, S. (2002). Pensions and the path to gerontocracy in germany. European Journal of Political Economy, 19, 153-158.

United Nations (2007). Population Division of the Department of Economic and Social Affairs of the United Nations Secretariat, World Population Prospects: The 2006 Revision and World Urbanization Prospects: The 2005 Revision. Accessed, May 19, 2008, http://esa.un.org/unpp. 


\section{CESifo Working Paper Series}

for full list see www.cesifo-group.org/wp

(address: Poschingerstr. 5, 81679 Munich, Germany, office@cesifo.de)

2409 Alexander Kemnitz, Native Welfare Losses from High Skilled Immigration, September 2008

2410 Xavier Vives, Strategic Supply Function Competition with Private Information, September 2008

2411 Fabio Padovano and Roberto Ricciuti, The Political Competition-Economic Performance Puzzle: Evidence from the OECD Countries and the Italian Regions, September 2008

2412 Joan Costa-Font and Mireia Jofre-Bonet, Body Image and Food Disorders: Evidence from a Sample of European Women, September 2008

2413 Thorsten Upmann, Labour Unions - To Unite or to Separate?, October 2008

2414 Sascha O. Becker and Ludger Woessmann, Luther and the Girls: Religious Denomination and the Female Education Gap in $19^{\text {th }}$ Century Prussia, October 2008

2415 Florian Englmaier and Stephen Leider, Contractual and Organizational Structure with Reciprocal Agents, October 2008

2416 Vittorio Daniele and Ugo Marani, Organized Crime and Foreign Direct Investment: The Italian Case, October 2008

2417 Valentina Bosetti, Carlo Carraro, Alessandra Sgobbi and Massimo Tavoni, Modelling Economic Impacts of Alternative International Climate Policy Architectures. A Quantitative and Comparative Assessment of Architectures for Agreement, October 2008

2418 Paul De Grauwe, Animal Spirits and Monetary Policy, October 2008

2419 Guglielmo Maria Caporale, Christophe Rault, Robert Sova and Anamaria Sova, On the Bilateral Trade Effects of Free Trade Agreements between the EU-15 and the CEEC-4 Countries, October 2008

2420 Yin-Wong Cheung and Daniel Friedman, Speculative Attacks: A Laboratory Study in Continuous Time, October 2008

2421 Kamila Fialová and Ondřej Schneider, Labour Market Institutions and their Effect on Labour Market Performance in the New EU Member Countries, October 2008

2422 Alexander Ludwig and Michael Reiter, Sharing Demographic Risk - Who is Afraid of the Baby Bust?, October 2008 
2423 Doina Maria Radulescu and Michael Stimmelmayr, The Welfare Loss from Differential Taxation of Sectors in Germany, October 2008

2424 Nikolaus Wolf, Was Germany ever United? Evidence from Intra- and International Trade 1885 - 1933, October 2008

2425 Bruno S. Frey, David A. Savage and Benno Torgler, Noblesse Oblige? Determinants of Survival in a Life and Death Situation, October 2008

2426 Giovanni Facchini, Peri Silva and Gerald Willmann, The Customs Union Issue: Why do we Observe so few of them?, October 2008

2427 Wido Geis, Silke Uebelmesser and Martin Werding, Why go to France or Germany, if you could as well go to the UK or the US? Selective Features of Immigration to four major OECD Countries, October 2008

2428 Geeta Kingdon and Francis Teal, Teacher Unions, Teacher Pay and Student Performance in India: A Pupil Fixed Effects Approach, October 2008

2429 Andreas Haufler and Marco Runkel, Firms' Financial Choices and Thin Capitalization Rules under Corporate Tax Competition, October 2008

2430 Matz Dahlberg, Heléne Lundqvist and Eva Mörk, Intergovernmental Grants and Bureaucratic Power, October 2008

2431 Alfons J. Weichenrieder and Tina Klautke, Taxes and the Efficiency Costs of Capital Distortions, October 2008

2432 Andreas Knabe and Ronnie Schöb, Minimum Wage Incidence: The Case for Germany, October 2008

2433 Kurt R. Brekke and Odd Rune Straume, Pharmaceutical Patents: Incentives for R\&D or Marketing?, October 2008

2434 Scott Alan Carson, Geography, Insolation, and Institutional Change in $19^{\text {th }}$ Century African-American and White Stature in Southern States, October 2008

2435 Emilia Del Bono and Daniela Vuri, Job Mobility and the Gender Wage Gap in Italy, October 2008

2436 Marco Angrisani, Antonio Guarino, Steffen Huck and Nathan Larson, No-Trade in the Laboratory, October 2008

2437 Josse Delfgaauw and Robert Dur, Managerial Talent, Motivation, and Self-Selection into Public Management, October 2008

2438 Christian Bauer and Wolfgang Buchholz, How Changing Prudence and Risk Aversion Affect Optimal Saving, October 2008 
2439 Erich Battistin, Clara Graziano and Bruno Parigi, Connections and Performance in Bankers' Turnover: Better Wed over the Mixen than over the Moor, October 2008

2440 Erkki Koskela and Panu Poutvaara, Flexible Outsourcing and the Impacts of Labour Taxation in European Welfare States, October 2008

2441 Marcelo Resende, Concentration and Market Size: Lower Bound Estimates for the Brazilian Industry, October 2008

2442 Giandomenico Piluso and Roberto Ricciuti, Fiscal Policy and the Banking System in Italy. Have Taxes, Public Spending and Banks been Procyclical in the Long-Run? October 2008

2443 Bruno S. Frey and Katja Rost, Do Rankings Reflect Research Quality?, October 2008

2444 Guglielmo Maria Caporale, Antoaneta Serguieva and Hao Wu, Financial Contagion: Evolutionary Optimisation of a Multinational Agent-Based Model, October 2008

2445 Valentina Bosetti, Carlo Carraro and Massimo Tavoni, Delayed Participation of Developing Countries to Climate Agreements: Should Action in the EU and US be Postponed?, October 2008

2446 Alexander Kovalenkov and Xavier Vives, Competitive Rational Expectations Equilibria without Apology, November 2008

2447 Thiess Buettner and Fédéric Holm-Hadulla, Cities in Fiscal Equalization, November 2008

2448 Harry H. Kelejian and Ingmar R. Prucha, Specification and Estimation of Spatial Autoregressive Models with Autoregressive and Heteroskedastic Disturbances, November 2008

2449 Jan Bouckaert, Hans Degryse and Thomas Provoost, Enhancing Market Power by Reducing Switching Costs, November 2008

2450 Frank Heinemann, Escaping from a Combination of Liquidity Trap and Credit Crunch, November 2008

2451 Dan Anderberg, Optimal Policy and the Risk Properties of Human Capital Reconsidered, November 2008

2452 Christian Keuschnigg and Evelyn Ribi, Outsourcing, Unemployment and Welfare Policy, November 2008

2453 Bernd Theilen, Market Competition and Lower Tier Incentives, November 2008

2454 Ondřej Schneider, Voting in the European Union - Central Europe's Lost Voice, November 2008 
2455 Oliver Lorz and Gerald Willmann, Enlargement versus Deepening: The Trade-off Facing Economic Unions, November 2008

2456 Alfons J. Weichenrieder and Helen Windischbauer, Thin-Capitalization Rules and Company Responses, Experience from German Legislation, November 2008

2457 Andreas Knabe and Steffen Rätzel, Scarring or Scaring? The Psychological Impact of Past Unemployment and Future Unemployment Risk, November 2008

2458 John Whalley and Sean Walsh, Bringing the Copenhagen Global Climate Change Negotiations to Conclusion, November 2008

2459 Daniel Mejía, The War on Illegal Drugs in Producer and Consumer Countries: A Simple Analytical Framework, November 2008

2460 Carola Frydman, Learning from the Past: Trends in Executive Compensation over the Twentieth Century, November 2008

2461 Wolfgang Ochel, The Political Economy of Two-tier Reforms of Employment Protection in Europe, November 2008

2462 Peter Egger and Doina Maria Radulescu, The Influence of Labor Taxes on the Migration of Skilled Workers, November 2008

2463 Oliver Falck, Stephan Heblich and Stefan Kipar, The Extension of Clusters: Differencein-Differences Evidence from the Bavarian State-Wide Cluster Policy, November 2008

2464 Lei Yang and Keith E. Maskus, Intellectual Property Rights, Technology Transfer and Exports in Developing Countries, November 2008

2465 Claudia M. Buch, The Great Risk Shift? Income Volatility in an International Perspective, November 2008

2466 Walter H. Fisher and Ben J. Heijdra, Growth and the Ageing Joneses, November 2008

2467 Louis Eeckhoudt, Harris Schlesinger and Ilia Tsetlin, Apportioning of Risks via Stochastic Dominance, November 2008

2468 Elin Halvorsen and Thor O. Thoresen, Parents' Desire to Make Equal Inter Vivos Transfers, November 2008

2469 Anna Montén and Marcel Thum, Ageing Municipalities, Gerontocracy and Fiscal Competition, November 2008 